\title{
Users' perspectives on Implanon in Malaysia, a multicultural Asian country
}

This article was published in the following Dove Press journal:

Open Access Journal of Contraception

15 February 2011

Number of times this article has been viewed

\section{Asmah Mastor \\ Si Lay Khaing \\ Siti Zawiah Omar \\ Department of Obstetrics and Gynaecology, University of Malaya, Kuala Lumpur, Malaysia}

Correspondence:Asmah Mastor Department of Obstetrics and Gynaecology, University of Malaya, Kuala Lumpur, Malaysia

Email asmahma@hotmail.com
Background: The primary objective of this study was to evaluate Malaysian women's perception, acceptance, and views on Implanon ${ }^{\circledR}$ as a contraceptive method. We also aimed to identify women who favor Implanon, their vaginal bleeding patterns, nonmenstrual adverse events, reasons for discontinuation, and effect of Implanon on breastfeeding.

Study design: This study followed up 140 women after insertion of Implanon at the University of Malaya Medical Centre by examination of their medical records and telephone interviews. User profile, discontinuation rate, reasons for choice of Implanon, discontinuation, menstrual and nonmenstrual side effects, and satisfaction rate were assessed.

Results: The average age of users was 34.7 years, and $94.2 \%$ were para 2 and above. The ethnic distribution of the women reflected that of the general Malaysian population. The majority had at least secondary education (94.2\%), with 41.2\% having a higher degree. All of the users reported that they chose Implanon because it does not need compliance, and $72.1 \%$ felt that Implanon was cost-effective in the long term. Most users (70\%) reported irregular menses and this was the main reason given for discontinuation. The vast majority reported an overall decrease in menstrual blood loss. Almost half (46\%) suffered prolonged bleeding/spotting, and infrequent bleeding was experienced by 71 users (50.7\%). Half of the women did not experience any nonmenstrual adverse events. The commonest complaint was weight gain, with the next most common complaints being hair loss, acne, headache, nausea, mood swings, and reduced libido. Most of the nursing mothers denied a reduction in breast milk. There was a high mean satisfaction score with Implanon.

Conclusion: Implanon is well accepted by Malaysian women despite a high incidence of irregular bleeding which was found to be a major concern among women who discontinued the implant.

Keywords: implanon, contraception, implant, etonogestrel

\section{Introduction}

Postpartum hemorrhage remains the major contributing factor to maternal mortality in Malaysia, due to poor spacing and multiparity. The appropriate use of contraception reduces the risk of unwanted pregnancy. Contraceptive implantation was devised to provide an ideal method of contraception, and research on this technique dates back to the $1960 \mathrm{~s}^{1}{ }^{1}$ The levonogestrel-releasing six-capsule system, Norplant ${ }^{\circledR}$, and the two-rod system, Norplant-II (Jadelle ${ }^{\circledR}$ ) were the only other widely marketed implants with established efficacy and safety prior to the advent of Implanon ${ }^{\circledR}{ }^{2}{ }^{2}$

Implanon is a single-rod implant ( $4 \mathrm{~cm}$ long, $2 \mathrm{~mm}$ in diameter) containing a core of etonogestrel (3-ketodesogestrel) $68 \mathrm{mg}$. The implant inhibits ovulation within one day of insertion and provides effective contraception for up to three years. There is no 
increase in the risk of ectopic pregnancy, fetal malformation, or impaired infant health in pregnancies conceived either during use of the implant or after its removal. . $^{3,4}$

Implanon is increasing in popularity because its insertion and removal is much easier and faster than with Norplant. In addition, previous studies have shown that complications associated with its insertion and removal are rare in the hands of medical professionals familiar with the techniques. ${ }^{5}$

Implanon was introduced in Malaysia in 2002. One year later, it was launched in the Family Planning Unit at the University of Malaya Medical Centre (UMMC). Because Malaysia is a multiracial country with different ethnicities, cultures, religions, and beliefs, the acceptance, perception, adverse events, and reasons for choice and/or discontinuation of Implanon may be different in Malaysian women from those in other studies, the majority of which have been done in Western countries.

The primary objective of this study was to evaluate Malaysian women's perception, acceptance, and views on Implanon as a contraceptive method. We also aimed to identify women who favor Implanon, their vaginal bleeding patterns, nonmenstrual adverse events, main reasons for discontinuation, and effect of Implanon on breastfeeding.

We hope that the findings of this study will contribute to future counseling of women who wish to use Implanon, particularly in Asian countries, where there are similarities in the characteristics of women living in these countries. We also anticipate that our findings will help to reduce the discontinuation rate and have a good impact on future national family planning programs.

\section{Material and methods}

In total, 140 women from the Family Planning Unit at UMMC who fulfilled the study criteria were interviewed via telephone by the main investigator. UMMC ethical committee approval was obtained prior to commencement of this study. Contact telephone numbers for Implanon users were obtained from their medical records.

The inclusion criteria for this study were women who had Implanon insertion between January 2003 and December 2006. They were all healthy women, aged over 18 years, sexually active, of child-bearing potential, had a regular menstrual cycle ( $28 \pm 7$ days with flow $7 \pm 2$ days), had no contraindications to the use of contraceptive steroids, and were contactable by phone. We excluded women who used Implanon for a noncontraceptive purpose, eg, menorrhagia, and those in whom Implanon was removed within three months of insertion.
During the interview, demographic data and past obstetric and contraception history were verified. Information specific to the use of Implanon was then obtained. Among the discontinuers, further information was sought regarding duration of Implanon use and the reason for stopping. Any changes in bleeding pattern and adverse events experienced were documented. Women who breastfed while on Implanon were asked about their perception of any changes in amount of breast milk. At the end of the interview, they were asked to give a score for Implanon in order to assess their satisfaction in an objective manner (the higher the score, the more favorable their view).

Adverse events were defined as any new complaints or symptoms emerging during the study period or any preexisting complaints or symptoms that increased in severity or frequency during use of Implanon. Bleeding pattern indices, as defined by the World Health Organization (WHO), indicate the extent of deviation from a normal menstrual cycle, and only those women who had at least one evaluable reference period of 90 days' duration were included in the analysis. We classified the types of bleeding changes experienced by each user according to the revised WHO definitions of bleeding patterns. ${ }^{6}$ Additional indices assessed in our study were shortened bleeding time, and increased or decreased menstrual blood loss. We defined amenorrhea as the absence of menstruation for three months or longer.

The data were coded and analyzed using SPSS/PC for Windows (version 12; SPSS Inc., Chicago, IL). The data were presented as mean \pm standard deviation (SD). The Chi-square test and independent Student's $t$-test were used to compare discrete and continuous variables, respectively. Significance was taken as $P<0.05$.

\section{Results}

Characteristics of subjects in this study are summarized in Table 1. The mean age of Implanon users was $34.7 \pm 5.3$ years, the youngest being 21 years and the eldest 48 years. The ethnic distribution of the women reflects that of the wider Malaysian population. Most users had at least secondary education (94.2\%) and most were career women $(62.8 \%)$. All users had at least one previous pregnancy. With regard to the source of information on Implanon, the majority of users $(62.9 \%)$ learned of the implant from medical personnel during counseling on contraception. All users chose Implanon because it does not need compliance, and $72.1 \%$ believed the implant to be cost-effective in the long term. More than half of the users had already completed their family. 
Table I Demographic characteristics of Malaysian women using Implanon

\begin{tabular}{|c|c|c|c|c|c|}
\hline Demographic & $\mathbf{n}$ & $\%$ & & $\mathbf{n}$ & $\%$ \\
\hline Age* & $34.7 \pm 5.3$ & & Miscarriage (n) & & \\
\hline$<30$ & 28 & 20.0 & 0 & 116 & 82.9 \\
\hline $31-35$ & 57 & 40.7 & I & 14 & 10.0 \\
\hline $36-40$ & 35 & 25.0 & $\geq 2$ & 10 & 7.1 \\
\hline$>41$ & 20 & 14.3 & & & \\
\hline Ethnicity & & & TOP (n) & & \\
\hline Malay & 98 & 70.0 & 0 & 134 & 95.7 \\
\hline Chinese & 28 & 20 & $\geq 1$ & 6 & 4.3 \\
\hline Indian & 7 & 5 & & & \\
\hline Others & 7 & 5 & Information source & & \\
\hline Educational level & & & Printed material & 32 & 22.9 \\
\hline Primary school & 8 & 5.7 & Internet & 10 & 7.1 \\
\hline Secondary school & 73 & 52.1 & Friends and relatives & 38 & 27.1 \\
\hline Higher education & 59 & 42.1 & Suggested by medical personnel & 88 & 62.9 \\
\hline \multicolumn{6}{|l|}{ Occupation } \\
\hline Housewife & 52 & 37.1 & Reason for choosing & & \\
\hline Career women & 88 & 62.8 & Need no compliance & 140 & 100 \\
\hline Household income & & & More economic in long term & 101 & 72.1 \\
\hline 2000 and below & 25 & 17.9 & Completed family & & 76 \\
\hline \multicolumn{6}{|l|}{54.3} \\
\hline $200 I-3000$ & 24 & 17.1 & Feels secure & 13 & 9.3 \\
\hline $300 I-4000$ & 24 & 17.1 & Weight gain with $\mathrm{OCP}$ & 3 & 2.1 \\
\hline $400 I$ and above & 67 & 47.9 & & & \\
\hline Parity* & $3.2 \pm 1.4$ & & Previous contraception & & \\
\hline One & 8 & 5.7 & OCP & 72 & 51.4 \\
\hline Two & 42 & 30.0 & IM Progestagen & 24 & 17.1 \\
\hline Three & 46 & 32.9 & Condom & 47 & 33.6 \\
\hline Four & 20 & 14.3 & IUCD & 23 & 16.4 \\
\hline \multirow[t]{2}{*}{ Five and above } & 24 & 17.1 & Withdrawal & 66 & 47.0 \\
\hline & & & Rhythm & 52 & 37.1 \\
\hline
\end{tabular}

Notes: *Mean \pm standard deviation.

Abbreviations: IM, intramuscular; IUCD, intrauterine contraceptive device; OCP, oral contraceptive pill; TOP, termination of pregnancy.

Forty-four percent of the women had used more than one contraceptive method before, eventually switching to Implanon, whereas $14.3 \%$ had never previously used any form of contraception. The majority of users had previous experience of steroidal contraception (68.5\%). Intramuscular injection of progesterone and a intrauterine contraceptive device were less popular choices.

A large number of the women reported irregular menses during use of Implanon (Table 2). More than one-third suffered from prolonged bleeding and spotting. However, despite a high incidence of irregular bleeding, most of the women $(71.1 \%)$ had an overall decrease in menstrual blood loss. Half of the Implanon users did not experience any nonmenstrual adverse event. The most frequent complaints were of weight gain, hair loss, headache, nausea, mood swings, and loss of libido. Sixty-two users were breastfeeding while they were on Implanon and $85.5 \%$ of them did not experience a reduction in amount of breast milk.

There was a high satisfaction score in Implanon users (mean $7.9 \pm 1.5)$. Nulliparas gave a higher score ( $8.8 \pm 0.8)$, compared 
Table 2 Menstrual and nonmenstrual effects of Implanon in Malaysian women

\begin{tabular}{|c|c|c|}
\hline & $\mathbf{n}$ & $\%$ \\
\hline \multicolumn{3}{|l|}{ Menstrual pattern } \\
\hline Amenorrhea & 32 & 22.9 \\
\hline Irregular & 98 & 70.0 \\
\hline Regular & 10 & 7.1 \\
\hline \multicolumn{3}{|l|}{ Change in menstrual loss } \\
\hline Increased menstrual loss & 9 & 6.4 \\
\hline Decreased menstrual loss & 101 & 72.2 \\
\hline No change in menstrual loss & 30 & 21.4 \\
\hline \multicolumn{3}{|l|}{ Bleeding frequency } \\
\hline No change & 37 & 26.4 \\
\hline Frequent bleeding & 32 & 22.9 \\
\hline Infrequent bleeding & 71 & 50.7 \\
\hline \multicolumn{3}{|l|}{$\begin{array}{l}\text { Specific adverse events } \\
\text { of Implanon }\end{array}$} \\
\hline Headache & 12 & 8.6 \\
\hline Nausea & 7 & 5.0 \\
\hline Vomiting & 2 & 1.4 \\
\hline Breast tenderness & 6 & 4.3 \\
\hline Loss of libido & 6 & 4.3 \\
\hline Mood swing & 7 & 5.0 \\
\hline Weight gain & 33 & 23.6 \\
\hline Acne & 14 & 10.0 \\
\hline Hair loss & 19 & 13.6 \\
\hline
\end{tabular}

with multiparas (mean $7.9 \pm 1.5$ ), but there was no statistically significant difference between these two groups $(P=0.06)$.

During the study period, 32 users (23\%) discontinued use of Implanon (Table 3). Among the discontinuers, the mean duration of Implanon use was 24 months. There was no discontinuation reported within the first six month of insertion and $25 \%$ of the users decided not to have another Implanon inserted after completing 36 months of usage. The most common reason for discontinuation was irregular bleeding (56.3\%) followed by a wish for further pregnancy (31.3\%). No user reported pain at the implanted site as a reason for discontinuation. The discontinuation of Implanon was not significantly related to age, ethnicity, parity, educational level, or socioeconomic factors (Table 4).

\section{Discussion}

The mean age of women using Implanon in our study was $34.7 \pm 5.3$ years, with $40 \%$ of them being older than 35 years and of mean parity $3.2 \pm 1.4$ years. Half of this group of women had already completed their family. These results suggest that women in this age group are the main users of Implanon, ie, women who do not want more children
Table 3 Duration of Implanon use in Malaysian women and reasons for discontinuation $(n=32)$

\begin{tabular}{lll}
\hline & $\mathbf{n}$ & $\%$ \\
\hline Duration of use (months) & 1 & 3.1 \\
6 to $<12$ & 8 & 25 \\
12 to $<18$ & 0 & 0 \\
18 to $<24$ & 11 & 34.4 \\
24 to $<30$ & 4 & 12.5 \\
30 to $<36$ & 8 & 25.0 \\
36 & & \\
Specific reason for discontinuation & 4 & 12.5 \\
Wish for tubal sterilization & 10 & 31.3 \\
Desired pregnancy & 0 & 0 \\
Pain at implanted site & 18 & 50 \\
Discontent with bleeding pattern & 8 & 25 \\
Nonmenstrual adverse events & 2 & 6.3 \\
Switching to another method & &
\end{tabular}

but are not yet ready for sterilization. One of the users was para 7, and the main reason she gave for using Implanon was that she had completed her family but was not keen for tubal sterilization at the age of 38 years. Thus far, there have been no similar published studies of Implanon in Malaysian women for comparison. However, studies have been done in neighboring countries in the South East Asia region, where the cultural background is similar to that of Malaysia. ${ }^{1,7,8}$

Our study suggests that Implanon is favored by middle- to upper-class women. Most of them gained information regarding Implanon from medical personnel during contraception counseling. This study demonstrates that Implanon is a choice made by women who have completed their family but still want effective contraception that requires no compliance and is cost-effective in the long term. This may contribute to the health care economy of the country, in view of a recent detailed cost analysis of all available contraceptive methods which concluded that despite their high initial purchase price, implants are more cost-effective than the combined oral contraceptive pill after one year of use. ${ }^{9}$

The minimum duration of assessment in this study was three months from the time Implanon was inserted. This was because we required at least one evaluable reference period of 90 days to assess bleeding patterns, whereby users would be able to describe their experience and give their overall view of Implanon after at least three months using it.

Consistent with the findings of a study from Thailand, ${ }^{7}$ the most common bleeding change experienced by users was infrequent bleeding/spotting. Implanon is probably a good contraceptive choice in Malaysian women of this age group 
Table 4 Discontinuation and characteristics of interest

\begin{tabular}{llll}
\hline Characteristic & $\begin{array}{l}\text { Continuers } \\
(\mathbf{n}=\mathbf{1 0 8})\end{array}$ & $\begin{array}{l}\text { Discontinuers } \\
(\mathbf{n}=\mathbf{3 2})\end{array}$ & P value \\
\hline Ethnicity & 77.1 & 22.9 & 0.62 \\
Malay & 78.6 & 21.4 & \\
Chinese & 100.0 & 0 & \\
Indian & 80.0 & 20.0 & 0.91 \\
Others & & & \\
Parity & 80.0 & 20.0 & \\
Nulliparas & 78.5 & 21.5 & 0.74 \\
Multiparas & & & \\
Educational level & 100.0 & 0 & 0.21 \\
Primary school & 75.0 & 25.0 & \\
Secondary school & 78.5 & 21.5 & \\
Higher level & & & \\
Occupation & 84.6 & 15.4 & \\
Housewife & 75.0 & 25.0 & \\
Career woman & & 15.8 & \\
Household income & & 28.1 & \\
$\leq 4000$ & 84.2 & & \\
$>4000$ & 71.9 & & \\
\hline
\end{tabular}

because it is associated with an overall reduction in menstrual blood loss and may be potentially beneficial for women with dysfunctional uterine bleeding who wish to practice contraception. Amenorrhea was reported to be the most common bleeding change in 200 Indonesian women, followed by infrequent bleeding/spotting. ${ }^{8}$ We found that there was variation in menstrual changes among Malaysian and Indonesian women, despite being in the same geographic region. Systemic analyses of randomized trials report that the bleeding pattern changes vary in different geographic regions. ${ }^{8,10}$

On the other hand, prolonged bleeding/spotting affected more than one-third of our study population and was found to be a major concern among discontinuers. They felt that their sex life was affected by this undesirable event and, if Muslim, they were unable to perform prayers or fasting. This factor would significantly impact on Implanon usage among Malaysian women, because many are Muslim. Menstrual changes would be expected with any form of progestin-only contraception, including Implanon. This led to discontinuation in $18 \%$ of Implanon users and was the main reason given by the discontinuers, which is consistent with previous findings. ${ }^{3,11}$

Overall, the majority of the users in our center experienced no serious adverse events while on Implanon. This favorable finding may be useful in future contraception counselling. The most commonly reported nonmenstrual adverse events observed in $8.6 \%$ to $23.6 \%$ of users were weight gain, followed by hair loss, acne, and headache. The less common adverse events were nausea, mood swings, breast tenderness, and loss of libido, which affected $4.3 \%$ to $5 \%$ of the users. Many of these symptoms are known side effects of hormonal contraception and of progestin contraceptive methods. ${ }^{12,13}$

An integrated analysis of nonmenstrual adverse events with Implanon reported that there were no consistent differences between countries, except that far fewer adverse events were reported in Indonesia and many more in Chile than in other regions. ${ }^{10}$ The countries involved in that study were Europe, Chile, Thailand, Singapore, and Indonesia.

There were no insertion- and removal-related adverse events, including infection, reported by our users, as in previous Implanon studies., ${ }^{3,5}$ Although insertion and removal of Implanon only involves a minor surgical procedure, medical professionals are strongly advised to familiarize themselves with the technique before undertaking these procedures on patients. The women should be adequately counselled, including the usual information on general advantages and disadvantages of implants, as well as knowledge of the insertion and removal procedures. The counseling should include the right to discontinue Implanon at any time, informing patients that implant site-related adverse events could occur, as well as clarification of the rapid return to fertility once the implant is removed.

Although we found that breast milk volume was not reduced by Implanon usage, our data were not objectively assessed, and instead were based on users' perception. However, this positive finding is supported by other studies comparing Implanon and nonhormonal IUCDs, showing no significant difference in breast milk parameters or infant growth. ${ }^{14,15}$

Implanon can be considered as one of the best contraceptive methods in the modern world, because insertion is simple and rapid, with immediate contraception when inserted on days $1-5$ of the menstrual period, with contraceptive efficacy for a period of three years. ${ }^{16-18}$

This study has some limitations. Only women contactable by telephone were interviewed. Some of the telephone numbers kept in the medical records were no longer in service. Our data were solely based on user experience and point of view. There was a difficulty in getting information regarding bleeding patterns, because we needed to define each of the indices for the user via a telephone conversation which may have resulted in recall bias. Attempts were made to keep this to a minimum by exercising objectivity. 


\section{Conclusion}

We found that Implanon was accepted well by Malaysian women despite a high incidence of irregular bleeding, which was found to be a major concern among discontinuers. Nevertheless, it is a very convenient, long-acting, reversible contraceptive method with minimal adverse effects and is accepted well by nursing mothers. In order to improve Implanon acceptance and reduce its discontinuation rate, we suggest that counseling prior to insertion should include topics such as advantages, disadvantages, and management of adverse effects, with strong emphasis on the expected changes in bleeding pattern.

\section{Disclosure}

The authors report no conflict of interest in this research.

\section{References}

1. Affandi B, Korver T, Geurts TB, Coelingh Bennink HJ. A pilot efficacy study with a single-rod contraceptive implant (Implanon) in 200 Indonesian women treated for $\leq 4$ years. Contraception. 1999;59:167-74. Retraction in: Rekers H, Affandi B. Contraception. 2004;70:433.

2. Biswas A, Biswas S, Viegas OA. Effect of etonogestrel subdermal contraceptive implant (Implanon) on liver function tests - a randomized comparative study with Norplant implants. Contraception. 2004;70(5):379-382.

3. Funk S, Miller MM, Mishell DR Jr, Archer DF, Poindexter A, et al. Safety and efficacy of Implanon, a single-rod implantable contraceptive containing etonogestrel. Contraception. 2005;71:319-326.

4. Glasier A. Implantable contraceptives for women: Effectiveness, discontinuation rates, return of fertility, and outcome of pregnancies. Contraception. 2002;65:29-37.
5. Mascarenhas L. Insertion and removal of Implanon. Contraception. 1998;58:79S-83S.

6. Belsey EM, Farley TMM. The analysis of menstrual bleeding patterns: A review. Contraception. 1988;38:129-156.

7. Booranabunyat $\mathrm{S}$, Taneepanichskul S. Implanon use in Thai women above the age of 35 years. Contraception. 2004;69:489-491.

8. Affandi B. An integrated analysis of vaginal bleeding patterns in clinical trials of Implanon. Contraception. 1998;58:99S-107S

9. National Collaborating Centre for Women's and Children's Health. Long-acting reversible contraception: The effective and appropriate use of long-acting reversible contraception. London, UK: RCOG Press; 2005. Available at: http://www.nice.org.uk/CG030. Accessed 26 March, 2010.

10. Zheng SR, Zheng HM, Qian SZ, Sang GW, Kaper RF. A randomized multicenter study comparing the efficacy and bleeding pattern of a single-rod (Implanon) and a six-capsule (Norplant) hormonal contraceptive implant. Contraception. 1999;60:1-8.

11. Harvey C, Seib C, Lucke J. Continuation rates and reasons for removal among Implanon ${ }^{\circledR}$ users accessing two family planning clinics in Queensland, Australia. Contraception. 2009;80:527-532. Available from: http://www.contraceptionjournal.org/article/S00107824(09)00300-X/abstract. Accessed March 26, 2010.

12. Urbancsek J. An integrated analysis of nonmenstrual adverse events with Implanon. Contraception. 1998;58:109S-115S.

13. Brachea V, Faundes A, Alvareza F, Cochona L. Nonmenstrual adverse events during use of implantable contraceptives for women: Data from clinical trials. Contraception. 2002;65:63-74.

14. Diaz S. Contraceptive implants and lactation. Contraception. 2002; 65:39-46.

15. Reinprayoon D, Taneepanichskul S, Bunyavejchevin S, et al. Effects of the etonogestrel-releasing contraceptive implant (Implanon ${ }^{\circledR}$ ) on parameters of breastfeeding compared to those of an intrauterine device. Contraception. 2000;62:239-246.

16. Herjan JT, Coelingh Bennink HJ. Presentation of clinical data on Implanon. Contraception. 1998;58:75S-77S.

17. Affandi B. Long-acting progestogens. Best practice and research. Clin Obstet Gynaecol. 2002;16:169-179.

18. Croxatto HB. Progestin implants. Steroids. 2000;65:681-685.
Open Access Journal of Contraception

\section{Publish your work in this journal}

Open Access Journal of Contraception is an international, peerreviewed, open access, online journal, publishing original research, reports, reviews and commentaries on all areas of contraception. In addition to clinical research, demographics and health-related aspects, the journal welcomes new findings in animal and preclinical studies

\section{Dovepress}

relating to understanding the biological mechanisms and practical development of new contraceptive agents. The manuscript management system is completely online and includes a very quick and fair peer-review system. Visit http://www.dovepress.com/testimonials.php to read real quotes from published authors. 